University of Warwick institutional repository: http://go.warwick.ac.uk/wrap This paper is made available online in accordance with publisher policies. Please scroll down to view the document itself. Please refer to the repository record for this item and our policy information available from the repository home page for further information.

To see the final version of this paper please visit the publisher's website. Access to the published version may require a subscription.

Author(s): Melanie Robinson

Article Title: Metalanguage in L1 English-speaking 12-year-olds: Which Aspects of Writing Do They Talk About?

Year of publication: 2005

Link to published version: http://dx.doi.org/10.1080/09658410508668819

Publisher statement: None 


\title{
Metalanguage in L1 English-speaking 12-year-olds: Which Aspects of Writing Do They Talk About?
}

\author{
Melanie Robinson \\ University of Warwick, UK
}

Traditional psycholinguistic approaches to metalinguistic awareness in L1 learners elicit responses containing metalanguage that demonstrates metalinguistic awareness of pre-determined aspects of language knowledge. This paper, which takes a more ethnographic approach, demonstrates how pupils are able to engage their own focus of metalanguage when reflecting on their everyday learning activities involving written language. What is equally significant is what their metalanguage choices reveal about their understanding and application of written language concepts.

Keywords: metalanguage, metalinguistic awareness, writing, written language

\section{Introduction}

The role and nature of metalanguage ${ }^{1}$ in bilingual children has been extensively researched and documented in the literature (see Jessner, this volume). However, the role of metalanguage in mother-tongue (hereafter L1) language learners has been much less considered. Moreover, the studies that do consider L1 metalanguage tend to do so only as an aspect of metalinguistic awareness, ${ }^{2}$ and focus on identifying the role of metalinguistic awareness in initial language acquisition (Bereiter \& Scardamalia, 1987; Cioffi, 1984; Dahl \& Freppon, 1995; Dyson 1989, 1991, 1992; Graves, 1983; MacGillivray, 1994). One possible reason for this focus is that is it assumed that metalanguage and metalinguistic awareness are more significant in initial language acquisition than at other stages of linguistic development. However, I would suggest that as language development remains far from complete after initial acquisition, the role of metalanguage in that development is fundamental. Having taught English in English secondary schools, and worked with the implementation of various editions of the National Curriculum: English (current edition DfEE, 1999) and the National Literacy Strategy document, The National Literacy Strategy: Framework for Teaching English: Years 7, 8 and 9 (DfES, 2001), it has become increasingly clear to me that the role of metalanguage is highly significant in the ongoing development of pupils' language abilities. Thus it seems that further study of the roles of metalanguage and metalinguistic awareness in that development is greatly needed. The aims of this research were to identify whether pupils used metalanguage or not when talking about their writing; and if they did, to then identify what kinds of metalanguage they used and what this revealed about their knowledge, thoughts and perceptions of language, and particularly about written language. 


\section{The Metalanguage of the L1 English Classroom}

Linguistic reflexivity, that is the use of language to talk about language, is a fundamental element of everyday linguistic interaction (see Berry, this volume). We could not ask What is your name? What did you say? Can you repeat that? How do you spell that? Is that true? and so on without the reflexive potential of language (see Harris, 1998; Taylor, 2000). However, the classroom, and in particular the L1 English classroom, involves its own discourse patterns (see Baker \& Freebody, 1989; Rampton et al., 2002), and these can make demands on metalanguage that are different from those of everyday linguistic interaction, as well as considerably raising the incidence of use of what may be regarded as typically 'everyday' metalanguage. This is of course due to the nature of teaching a language subject, but this paper focuses on the specific metalinguistic environment of the L1 language classroom. In England and Wales this is largely determined by the requirements of the current National Curriculum: English (1999) documentation.

It is true to say that much of this discourse will be replicated in other subject classrooms where pupils have to pay attention to language for the purposes of expressing what they have learned. For example, in a science lesson pupils may have to pay attention to the report genre in which they have been instructed to write, and therefore the teacher will have used metalanguage, or more precisely metalanguage terminology, ${ }^{3}$ even if as basic as the word report; in history they may write a diary of a historical figure, such as Henry VIII, and therefore may use metalanguage terminology such as diary, sentence, paragraph, vocabulary, and so on. However, the nature of L1 language teaching in literate societies will incur two specific elements of language use that are not generally discussed outside of that classroom. These two aspects are literature and what is commonly termed 'creative writing'. Both require pupils to reflect on knowledge of language as the subject itself, and to use it to create or appreciate aesthetic effects. In other subject classrooms language is generally used to express what has been learned. The elements of literature and creative writing add a further dimension to metalanguage that will be used in the L1 English classroom: the figurative dimension. This is in addition to the extended range of metalanguage that is required to deal with talking intensively about language, as is required in the L1 English classroom, especially since the implementation of the government initiatives noted above. For example, in the L1 English classroom the discourse will involve metalanguage terminology about figurative language such as metaphor, simile, prose, stanza, and so on; but will also draw on the language that describes a writer's structural techniques, such as structure or punctuation, or speech characteristics such as tone, pace, articulation, and so on. Pupils' development of these L1 skills until the age of 16 is documented in the government publications noted above; therefore, it is anticipated and expected that pupils' metalanguage will necessarily increase in sophistication and application until this age at least. ${ }^{4}$ Although this seems fairly obvious, it is the basis on which I make the claim that it is important to conduct research into the metalanguage and metalinguistic awareness of children in this age range. This paper therefore considers the role of metalanguage in English L1-learning 12-year olds. 


\section{Language and Metalanguage}

Human language is necessarily reflexive, that is, metalanguage is a natural element of language. No other phenomenon has the level of reflexivity that language does (although there are 'metalanguages' within many academic and technical fields, these are not true metalanguages, because the metalanguage terminology itself is not self-referential: see Harris $(1996,1998)$ for further discussion). One of the consequences of this is that metalanguage used by teachers and academics is the same as that used by ordinary people in everyday linguistic interaction. Teachers and academics tend to use metalanguage to analyse instances of words, and often (though by no means exclusively) those written on a page. As a result, metalanguage has become both deterministic and specialised - to some extent, it has become metalanguage terminology. Lay language users tend to come to understand that such terminology is used to 'label' language; for example, 'table is a noun'; or that terminology is specialised and they do not understand it, for example onomatopoeia, colon, apostrophe (see Davis, $2001,2003)$. It is therefore very important to consider what is 'lay' metalanguage, and what is 'professional' metalanguage to understand that a two-tier system of metalanguage appears to have developed (see Davis, 2001, 2003; Harris, 1996, 1998; Taylor, 2000, 2003 for further discussion).

The metalanguage of the L1 English classroom becomes increasingly specialised during the secondary school years (ages 11-16 in England and Wales). Indeed, it seems that what pupils have to learn to achieve a GCSE qualification veers more and more towards what may be considered to be 'professional' metalanguage. This paper explores the significance of metalanguage in relation to pupils' written language ability (as measured by the English National Curriculum level descriptors for writing [DfEE, 1999]) and written language experiences.

The overall aim of this study was to elicit pupils' metalinguistic awareness of their own writing. It was anticipated that metalanguage would form a fundamental part of that awareness, and this paper explores the pupils' uses of metalanguage, metalanguage terminology, and their role in talking about writing.

\section{Methodology}

The data was collected as part of a wider study of pupils' metalinguistic awareness, and involved case-studies of eight pupils aged 12 who attend a comprehensive secondary school in Birmingham. Seven of the eight pupils were monolingual speakers of English, while the eighth was a bilingual speaker of English and Chinese for whom English was the dominant language. I was known as a recent ex-teacher to the pupils. However, the fact that I was no longer employed there meant that I did not have the same power relations with the pupils that I had when I was a teacher, and pupils were encouraged to talk honestly in response to all questions, as there would be no classroom repercussions, and no teachers would be given any information that the pupils provided. They were also encouraged to explore further any issues they wished to that were raised during the interviews. The complete data includes:

(1) two detailed interviews with each pupil (the first of which was semi-structured, and covered attitudes to writing, reading and writing life history, 
knowledge about written language, writing processes and value of ownership);

(2) analysis of a wide range of samples of pupils' written work; and

(3) a test of pupils' receptive metalanguage.

The metalanguage terminology that the pupils used was elicited from the interviews and the test.

The pupils ranged in writing ability from one working at National Curriculum level 6 (above average for chronological age) to three working at level 2 (well below average for chronological age), and included two dyslexic pupils. The pupils' writing abilities, as measured by National Curriculum level descriptors, were as shown in Table $1 .^{5}$

To elicit the pupils' receptive metalanguage, a test was carried out at the beginning of the second interview with each pupil to elicit which elements of common school metalanguage terminology pupils knew. Pupils were presented with 64 written items (metalanguage terminology) one at a time. They were asked to read the item if they could, then to explain what they thought it means. If the pupil could not read the item, I read it to them, and then asked them what they thought it means. The items presented in the test were terminology taken entirely from the National Curriculum (1999) to ensure that they were within the terminology that teachers should be using with pupils, and therefore that pupils should be familiar with. No other metalanguage was presented in this test, although other metalanguage would have been used throughout the interviews as arose within the discussion, and within this test that the pupils used to talk about the metalanguage they were presented with.

The functions of this test were threefold:

(1) to gain some idea of the terminology that the pupils know but possibly do not use (for example, that is used in the classroom by the teacher);

(2) to elicit their own comments about such terminology to see how they understand it at that point in time;

(3) to identify whether the terminology pupils individuals are able to employ accounts for the concepts they apply when writing themselves.

Responses were judged to be indicative of understanding of the concept if the pupils were able to explain what the term presented meant to them, and if their definition or explanation went some way towards a conventional understanding of that concept. In this study a response is taken to be a pupil's verbal reaction to either a question, to their own pieces of writing, or to a word presented to them in the receptive metalanguage test. Metalanguage terminology in the pupils' responses is taken to be lexis (a word or phrase) that refers to an item of language or a language function, such as noun, sentence, rhyme, comma.

Table 1 National Curriculum levels for writing per pupil

\begin{tabular}{|l|c|c|c|c|c|c|c|c||}
\hline Pupil & Pupil 1 & Pupil 2 & Pupil 3 & Pupil 4 & Pupil 5 & Pupil 6 & Pupil 7 & Pupil 8 \\
\hline Level & 6 & 5 & 4 & 3 & 3 & 2 & 2 & 2 \\
\hline
\end{tabular}




\section{Findings 1: General}

All the pupils employed metalanguage in a high proportion of their responses (to both the interviews and the receptive metalanguage test), thus clarifying the initial object of the study: to identify whether all the pupils are able to explicitly demonstrate metalinguistic awareness. The pupils clearly demonstrated that they are able to use appropriate terminology to reveal some of what they know about language. Even the weakest writers utilised terminology in a high proportion of their responses.

\section{Findings 2: Receptive Metalanguage}

It is interesting to see to what extent the pupils used terminology (Table 2). Pupil 1, the highest achieving writer, used terminology in only $88 \%$ of his responses; this is comparable to that used by Pupils 7 and 8 , at the opposite end of the ability spectrum, who used terminology in $85 \%$ and $82 \%$ of responses respectively. Although I am unable to make any firm claims about it, I would suggest that there are probably very different reasons for this. From my experience I found that it is likely that Pupils 7 and 8 employed less terminology than other pupils because their responses were more colloquial, and this in turn may be because they do not have extended metalanguage terminology to draw upon. For example, Pupil 8 (Int = interviewer):

Int: Just have a look at some of your other Science work, and tell me how is it different from English work? How does it look different, what do you do differently?

Pupil 8: You don't put sentences you just put like, little, words to describe what you was going to put.

Int: What does that (TEXT) mean?

Pupil 7: Objects like words and sentences.

However, for Pupil 1 it is often the case that he did not utilise as much terminology because he makes implicit metalinguistic responses by way of cohesion in the articulation of his responses. For example:

Int: So what do you think a paragraph is?

Pupil 1: A paragraph, it's a group of sentences put together, (2.0) that's it.

Int: So what makes us decide which sentences go together in a paragraph?

Pupil 1: Based on the same theme, you're talking about the same thing, so you put it in a paragraph, then you change subject, and you just put it in a new paragraph.

In this example he used pronouns to refer by anaphora to the terminology the interviewer has referred to (see Halliday \& Hasan, 1976). These enabled him to discuss judgements about language without having to specify that language

Table 2 Percentage of pupils' responses containing metalanguage terminology

\begin{tabular}{|l|c|c|c|c|c|c|c|c||}
\hline & Pupil 1 & Pupil 2 & Pupil 3 & Pupil 4 & Pupil 5 & Pupil 6 & Pupil 7 & Pupil 8 \\
\hline \% of responses & 88 & 91 & 95 & 97 & 93.5 & 93 & 85 & 82 \\
\hline
\end{tabular}


himself first (Hannan, 2001). This pattern is reflected across the ability range; Pupil 2 did not make use of terminology in 9\% of responses, while the middle-ability pupils' responses apparently have a higher quantity of terminology. It must be noted here that pupils' responses were not balanced in terms of the number analysed for each pupil. This is because all pupil responses that contained metalanguage terminology were analysed, irrespective of how many they provided. The value was felt to lie not in a quantitative analysis of the amount of terminology used, but rather the quality and application of that terminology. It would therefore seem that investigation into the nature of metalanguage and metalanguage terminology used by children is necessary to find out if this is a significant factor in later linguistic development.

Of the 64 items that they were tested on, the pupils were able to respond in a way that indicated that they have some understanding of that concept, as shown in the number of instances in Table 3.

It is clear that Pupil 1 was aware of the most metalanguage terminology, which appears to reflect his position as the most able writer in the cohort. However, the other pupils' results are so similar that they indicate that knowledge of terminology does not seem to significantly reflect differences of ability in writing. It can be seen that the terminology that Pupil 2 is aware of (in terms of the number of items she could respond to appropriately) is the same as Pupil 5, yet their written language abilities differ greatly. Indeed, both pupils' comments about terminology are the weakest across the cohort, although in reality there seems to be little to choose between the seven pupils (here excepting Pupil 1) in terms of the amount of terminology they know; they are very closely balanced, despite their differing writing abilities.

It could be suggested from this data that the amount of terminology a pupil knows reflects no correlation to writing ability except possibly at higher levels of achievement. This warrants further study. The parallels between what the pupils could not explain adequately are also significant: the seven pupils with similar performance in this test could not explain terminology such as monologue, genre, narrative, prose, metaphor, alliteration, simile, imagery, onomatopoeia, personification, adverb, syllable, semi-colon, apostrophe. The terminology that pupils have is very important, as it demonstrates that pupils have at least some awareness of metalinguistic concepts that they may not reveal through their own use of terminology. This is particularly relevant from the teacher's perspective. It is easy to assume that because a pupil never uses a particular metalanguage term that they do not possess that concept. However, L1 English teachers use a wide range of terminology with each class they teach, and pupils will have some receptivity to this, even if they do not use it themselves.

Table 3 Percentage of responses that were relevant to the word presented

\begin{tabular}{|l|c|c|c|c|c|c|c|c||}
\hline & Pupil 1 & Pupil 2 & Pupil 3 & Pupil 4 & Pupil 5 & Pupil 6 & Pupil 7 & Pupil 8 \\
\hline $\begin{array}{l}\text { Responses as } \% \\
\text { of total }\end{array}$ & $89 \%$ & $53 \%$ & $63 \%$ & $61 \%$ & $53 \%$ & $63 \%$ & $56 \%$ & $58 \%$ \\
\hline
\end{tabular}




\section{Findings 3: Productive Metalanguage}

This is metalanguage that was produced during the course of two interviews I conducted with each pupil, not including any that had been used by the interviewer in the immediately preceding question, nor that used in the metalanguage terminology test.

From a pedagogic perspective the pupils' use of metalanguage is a significant aspect of the study. Not only is it significant in revealing the metalinguistic concepts they know, but also the pupils' perspective of so much of their written work is revealed in their metalanguage. The pupils' responses analysed in this study were selected because they contained metalanguage; as a result, the amount of data analysed per pupil was not equal. However, as the focus of the analysis is on the qualitative implications of the data, this was not a significant factor; firstly, all the pupils were asked the same initial questions in the semi-structured interviews (regarding attitudes to writing) and indeed, the data reveals that the significance lies in what the pupils said about or using metalanguage and the nature of that metalanguage, rather than the frequency of occurrence.

The pupils' metalanguage referred in general to four aspects of written language:

- sentence;

- paragraph;

- spelling;

- punctuation.

The discussion below gives a flavour of some of their responses, and more importantly, what their use of metalanguage reveals about the way they think about writing. However, only some of the responses can be presented in this paper.

\section{Pupil comments about sentence}

Sentence is a very difficult concept to teach. L1 pupils learn to write the mechanics of sentences long before they learn the explicit grammatical structure of sentences, function, and so on. The pupils commented on sentence in several ways. Some responses indicated that pupils are implicitly aware of a function of sentences. For example, Pupil 8 talked about how her favourite kind of writing was answering questions:

Pupil 8: I find it more of a challenge, writing, and I know what I'm going to put 'cause I know the answer and I know how to put it.

Int: How do you know how to put it?

Pupil 8: 'Cause you just write in sentences and put it together so it makes sense.

There seems to be an implicit awareness in this response that sentences and 'making sense' are linked, although without reasons why or an attempt to explore why this is. Another pupil expressed a similar concept of the function of sentences, although in conjunction with other aspects of the concept:

Int: What do you think a sentence is?

Pupil 1: A sentence is a group of words, together, and it's got to make sense. And it has to be, has to start with a capital letter and end with a full stop. 
This idea of sentences linked with sense appears to be one that is shared, even among pupils of differing abilities. This pupil also notes the orthographic conventions he is aware that sentences require; this was another aspect that pupils focused on frequently. Pupil 2 talks about lessons where she is taught to use the orthographic conventions of sentences:

Pupil 2: I don't like it when the lesson's about them.

Int: What kind of things do you have to do in those lessons?

Pupil 2: Em, say 'cause we did letters [i.e. a letter to someone] and we were putting sentences and we had to add them in and that was really boring 'cause I already knew all of that.

This is a significant teaching point; this pupil does not like work of this nature, indeed seems to regard it as beneath her or insulting somehow. Significantly, this raises an affective element to language awareness. Yet the teacher must have felt that she needed to review and/ or consolidate some of this knowledge. Had the teacher known she felt like this, he may have tried a different strategy.

Another useful consideration for teachers is how pupils understand the concept of sentence. Take Pupil 2 for example:

Pupil 2: Sentence (response to metalanguage terminology test).

Int: Which means?

Pupil 2: A line of writing.

Int: Just one line?

Pupil 2: It could be a couple of lines, but it could have, full stop, it can only have one full stop in it but it can have many commas.

This pupil's initial response is a visual one. Upon further questioning she uses knowledge of orthographic conventions to develop her definition. However, she also applies a range of knowledge of orthographic conventions to her response, and makes an effort to explicitly explain how punctuation is used differently in sentence, implying a difference in their functions. If teachers were aware of the visual perspective, this might change the way they approach their teaching. Pupil 2's development of this point may make the teacher want to explore this concept further; in other words, there are many conceptions of the same term, which teachers could explore differently with pupils if they were aware of them.

Other concepts of sentence are linked not to writing, but implicitly to reading and articulation:

Int: What if we had something you could understand but it went on and on and on and on, and it didn't get a full stop until the bottom of the page, would that be a sentence?

Pupil 5: No.

Int: Why not?

Pupil 5: 'Cause it wouldn't have really really long talking and then you have to put all the full stops in the right places.

Int: How do you know where to break it up?

Pupil 5: Like say that you're talking and you're doing your sentence, find where you just breathe and put a full stop where you breathe. 
Other pupils made comments about sentence based on their knowledge of the generic conventions they encounter in their writing at school:

Int: Do you write about Science in the same way as you write about History?

Pupil 8: No, keep it different stuff.

Int: So it's different information - but do you use language the same way, do you put words together the same way?

Pupil 8: Yeah, sort of, most of the time. Depends what we' re writing, because in Science we might be writing sentence and codes and stuff like that, but in History we might be writing paragraphs or something like that.

The pupil demonstrates a clear awareness that in different subject areas, she uses writing to fulfil different functions, and that this has implications for her in terms of how she structures that writing. This operates above at a level of textual organisation. Below, she applies the same awareness to another form of writing, a table:

Int: Now, look at this table. How does this help to organise your writing?

Pupil 8: You know where you've got to put it in a sent (sic), not a sentence, you've just got to put little notes, and it's easier.

Int: $\quad$ So why don't you need sentences?

Pupil 8: Because you don't need to write big long bits of a sentence, it's notes because it's not a long thing, it's only little.

Her awareness is not so advanced that she is able to explicitly formulate a reason why she has to write differently; however, the fact that she is aware of the differences is significant pedagogically. Note also that she struggles to find terminology in her final response, 'because it's not a long thing'; yet somehow we know what she means, referring implicitly here to something like phrase. This raises another issue that should be considered in studies of this type: to what extent can we expect people, whether children or adults, to be able to explicitly verbalise their metalinguistic judgements? It is difficult to verbalise aspects of our intuitive knowledge about language as professional linguists at times, and we are aware of the extent to which we depend upon terminology to do so. Pupil 8 should not, I would suggest, be considered unaware just because she does not have the terminology she needs; her language is metalanguage at the point above. Other pupils responded similarly:

Int: (Referring to a piece of the pupil's written work from science) ScienceResistance. When you' re writing in a subject like Science, how is it done differently to writing in English work?

Pupil 1: We don't have to write in sentences, and you can do diagrams and stuff.

Even the most able writer, who demonstrated above that he has the widest range of terminology among the cohort, has to revert to a colloquial term, 'stuff', to express his ideas about genre and sentence. These comments about sentence reflect the range of ways that pupils think about what is possibly the most difficult concept in L1 language teaching, that is, what is a sentence? It would be 
useful if teachers considered this from their pupils' perspectives, which are essentially practical, when teaching how to write them, develop them, etc.

\section{Pupil comments about paragraph}

Paragraph is again difficult to teach conceptually, so children are often taught how to make sentences look like paragraphs before they know what the functions of paragraphs are. This is because paragraph is essentially an abstract concept when we are producing them; they are easy to recognise visually on the page, but what they are and what they do is much more difficult to apply when writing oneself. However, the pupils had a lot to say about paragraph, especially related to the process of using them:

Pupil 5: Paragraph (response to metalanguage terminology test).

Int: What does that mean to you?

Pupil 5: When you're starting a new scene or another room when you' re writing about something and you go into another room you start another paragraph.

In this response she indicates that she knows that she has to change paragraphs when she changes an aspect of the content of her writing. This response is implicit, in that she does not explain why she is changing paragraph in a functional sense, but rather in a situational sense (see Ong, 1982), that is, related to what she does in a given situation. The latter response is implicit; an explicit response would indicate what she does in a generic sense in relation to paragraphs. Another pupil talks about paragraphs in his writing process:

Int: What about when you' re writing, how do you know when to write a new paragraph?

Pupil 4: Don't know.

Int: Do you use paragraphs when you write?

Pupil 4: [shakes head]

Int: Never ever?

Pupil 4: I only use full stops and capital letters, and commas and that.

Int: What else do you use?

Pupil 4: All the rest except paragraphs.

Int: All the rest, but not paragraphs. Why not?

Pupil 4: Because I keep on forgetting. It's just a piece of work that you forget to put a few in.

Int: So you know how to use them?

Pupil 4: [Nods]

Int: You just forget?

Pupil 4: Yeah.

This response is much more generic, as Pupil 4 relates his inability to use paragraphs to all of his writing. His response is possibly indicative of the process of development that occurs in learning writers; that there are some concepts he has mastered, such as the use of punctuation that he cites, but there are also elements that he has to 'remember' to use, which in other words he is still learning. From a pedagogic perspective it would be useful to find out why he struggles to remem- 
ber to use paragraphs; it may be for example that he cannot remember how to indent (many of English-speaking L1 pupils do not fully understand the conventions of paragraphing, for example they are used to block format in letters, etc. and so often miss a line rather than indenting a sentence to indicate a new paragraph), or that he has not yet fully understood their function. Until the writer is aware that paragraphs have a function for the reader, possibly more so than for the writer (who can interpret their own structural systems in writing), it is unlikely that he/she will begin to see their function within their own writing which, at school especially, is often only for the eyes of themselves and the teacher.

Another pupil's response indicated some awareness of the process of using paragraphs, but also of their function as he does so:

Int: So to show them that you were asking them questions and things you've had to use quite a range of punctuation. How else have you tried to make clear what you've done where?

Pupil 1: I've done paragraphs, to separate them, and did numbers.

This concept of function, as already argued, seems to lie at the core of successful writing in relation to a concept of paragraph. It is also significant to see that paragraphs are discussed by this pupil as an action when he responds in terms of process; it is something he 'does' when he is writing. However, again metalanguage terminology would have made this response more explicit ('to separate them'). The functions of paragraphs were explored by other pupils who had even less terminology, but who still successfully, if implicitly, communicated awareness of what she does:

Pupil 8: Text (response to metalanguage terminology test).

Int: What does that mean to you?

Pupil 8: Do like a paragraph, of what you're going to write it's only little so it makes it shorter, you've made a big paragraph you make a little one to make it understandable and you don't have to read the big one.

Although very complicated, possibly due to lack of other terminology, this pupil's response implicitly shows that she is aware that she is breaking down her writing into units that are at least visually accessible for the reader. This demonstrates a crucial point about terminology; although a sophisticated metalanguage vocabulary is often lacking in the pupils, they find a way of expressing their awareness of language. Pupil 8 is clearly aware of a function of paragraphs, albeit at a fairly superficial level.

\section{Pupil comments about spelling}

Spelling was a very important issue to all of the pupils. Their talk about spelling revealed that most of them have a very strong feeling that their work is judged mostly on their ability to spell correctly, and that this is an over-riding concern of theirs when they are writing at school:

Pupil 3: Spelling (response to metalanguage terminology test).

Int: What does that mean? 
Pupil 3: Em, spell, something, you need either you need to check it or something like that because you've spelt it wrong.

This response reflects many of those about spelling given by the pupils; indeed, every pupil in the cohort gave at least one response that indicated that they feel that spellings must be 'correct'. Their responses also indicate that they take this very personally, as if they feel that if they are not a good speller, they cannot be a good writer:

Int: Ok. What does it mean to be 'good' at writing then? If you thought of a person who is good at writing, what kind of things can they do?

Pupil 6: They've got, they can write things really good, like without any spelling mistakes, like they can easy write what they're thinking of and what they mean.

Thus it seems that spelling and self-esteem are very much related in the pupils' attitudes towards themselves as writers. The only pupil for whom spelling does not seem to be an issue of importance is Pupil 1:

Int: What does the teacher do to show you you've got spelling mistakes?

Pupil 1: Er, puts a circle and puts 's / $p$ '.

Int: $\quad$ So you have to work out yourself where you've gone wrong?

Pupil 1: Yeah.

Int: How do you feel then about not being a brilliant speller?

Pupil 1: Don't really mind actually, I just try my best.

This is of course the most able writer in the cohort. It may be that as a writer he has realised that his work is assessed for more factors than just his spelling; this realisation may be a crucial part of the developmental process. Again, this warrants further study.

The importance placed on spelling by the pupils is best summarised by them. When they were asked at the end of interview one what the most important thing about writing is, they responded:

Pupil 3: Spellings and punctuality (sic)

Pupil 4: Handwriting... And spelling.

Pupil 7: Spelling

Pupil 8: That you know what it says and the spelling.

\section{Pupil comments about punctuation}

Punctuation is one of the most significant aspects of written language for teachers, as attempting to master the use of a range of punctuation can be a very slow, and often fruitless process for pupils. From this study's perspective it is important because punctuation is one of the conventions of the written language form that separates it most obviously from speech.

Some pupils referred to punctuation as part of the process of writing:

Int: What kind of things do you sometimes have to think about, not always but sometimes when you're writing?

Pupil 5: (6.0) like, speech bubble, no not bubbles marks, and capital letters like when you're just writing and you forget to put them in, and full stops. 
Int: And what kind of things do you always have to think about every single time you write?

\section{Pupil 5: Capital letters.}

This response indicates that using punctuation is not integral to the writing process for her, it is an additional extra that she knows she is expected to do, revealed by her admission that she 'forgets'. What is also significant is that she reveals that she has to think about what might be regarded as the most basic punctuation [using capital letters] every time she writes. It would seem that she has not truly assimilated their function when she writes, and thus even at the age of 12 she still has to think about using them. Another pupil responds on a completely different level about punctuation in the process of writing:

Int: Do you express your meaning differently when you're writing, do you think?

Pupil 1: Sometimes I do, when I write in big letters, and exclamation marks.

Int: And why do you do that?

Pupil 1: 'Cause I want to get their attention.

Int: Are there any other kinds of things you do like that when you're writing.

Pupil 1: (1.0) put a question mark, and then an exclamation mark.

Int: What effect does that have on the reader?

Pupil 1: Like, exactly ... don't know.

This response is not just about the process of using punctuation, it also indicates clear pragmatic awareness, that is what effect he intends to create for his audience. Thus, talk about punctuation when it is used ranges widely in this study, and indicates that analysis of just the types of metalanguage terminology that the pupils use is not sufficient indicator of metalinguistic awareness; the ways in which they apply that terminology is crucial.

Punctuation was also talked about in terms of its function, and its personal value to the pupils:

Int: How do you know where to break it [a sentence] up?

Pupil 4: Like say that you're talking and you're doing your sentence, find where you just breathe and put a full stop where you breathe.

As earlier, this response is functional, but really in relation to articulation, not writing.

Int: What makes you feel proud of your writing?

Pupil 5: When I've got a good mark.

Int: Do you ever just do work and think 'I'm proud of this anyway'?

Pupil 5: Sometimes.

Int: What is it about your work that you've done that makes you think that?

Pupil 5: Em, like when I've put like some punctuation in the right places.

Like spelling, the use of punctuation is something that is regarded as 'correct' by the pupils, and which those of lower ability feel is something to aspire to using.

Other responses indicated pragmatic awareness of using punctuation, such as when writing for different audiences: 
Int: If you had to write a letter to write a letter to $\mathrm{Mr}$ (headteacher) and a

Pupil 2: No. letter to your friend, would they be written in the same way?

Int: Why not?

Pupil 2: 'Cause it would be 'Dear Sir, Madam', and to a friend it would be 'To'.

Int: $\quad$ Any other differences?

Pupil 2: Yeah, you wouldn't put the address.

Int: In which one?

Pupil 2: The friend.

Int: Anything else? What about the actual letter itself?

Pupil 2: I could actually not put punctuation in as you would when writing a letter to $\mathrm{Mr}$ (headteacher).

Finally, punctuation was something that was mentioned in relation to editing work:

Int: What kind of things do you try to change when you're re-drafting?

Pupil 4: Try and change my punctuation.

Int: What about your punctuation do you try and change?

Pupil 4: Well em different ways. Well sometimes if it's like a word that is important, sometimes we do capital letters and then underline it.

The wide range of response types to punctuation seem to indicate that pupils have many ideas about its function, use and application in their own writing. However, it may be that this range of ideas is what holds them back from using a range of punctuation appropriately; there is just too much to think about when they are still developing their skills.

\section{Conclusions: LI Metalanguage, Teaching and Learning}

The elements of metalanguage terminology that the pupils seemed to be lacking most, irrespective of writing ability, are those which refer to figurative language. This element is a significant feature of successful candidates at GCSE in both the English and English Literature examinations (see Myhill, 2001 for a detailed analysis of what successful pupils do with language). It may be because this is the aspect that is furthest from that made use of everyday, and more like the terminology used by 'professionals' that this is why the pupils had such poor knowledge of it. However, it may also reflect a general trend that reading is declining as a children's pastime, in favour of video-style games. More research is necessary into this area, but it remains a significant one, for it is in this area that the pupils need terminology with which to cope with exams at least, and to appreciate aesthetic aspects of language in literature, film and art as into adult life, as well as to be critically aware of the thousands of media texts they will be exposed to every day.

The elements of metalanguage terminology that pupils use are very significant from a pedagogic level. It can be clearly seen that firstly, pupils who do not have terminology with which to refer to language concepts do not simply refrain from talking about them; they may have to use more colloquial terms, but they get their messages across. This means that children possibly need more practice in using this terminology, rather than just having it said to them by the teacher; 
and also that ability to use such terminology does not mean that a pupil is more aware or advanced in their skills than a pupil who cannot. However, it must also be recognised that having a developed terminology must give a pupil an advantage in being able to refer to their own language more explicitly.

It is also evident that use of metalanguage terminology in itself is not indicative of higher ability. The ways in which terminology is applied must be examined thoroughly, as the pupils' responses above indicate that terminology is applied in ways that refer to language structure and form, but that also refer to their own personal experiences of language, some of which are highly affective. It is not enough to examine frequency of application of terminology, nor to consider isolated examples of which terms are used. This again has pedagogic implications; teachers can elicit much about the ways in which pupils approach and conceptualise writing by talking to them about the concepts they are expected to apply on a daily basis in the classroom. However, it is also true to say that metalanguage has a crucial role in the delivery of L1 English teaching; as noted earlier, the almost 'professional' metalanguage that pupils have to understand and make use of at GCSE is now reflected in the new Framework for Teaching English: Years 7,8 and 9, and is indicated in the areas of receptive metalanguage that the pupils could not respond to which, as indicated above, tend to fall into the figurative metalanguage category. So to enable pupils to achieve higher grades at GCSE, although an advanced metalanguage is not indicative of L1 language ability, it is a significant factor in accessing the curriculum at that level.

This study offers the following insights to L1 language teachers in secondary education:

- That pupils need to develop their metalanguage terminology so as to be able to refer to concepts that affect them both in terms of lesson delivery and application to their own writing.

- That pupils need to learn to use terminology for themselves, rather than listening to the teacher using it.

- That pupils can provide teachers with a wealth of understanding about how they approach and perceive writing tasks; sometimes it is easy for the teacher to forget that we do not all approach writing the same way, and that pupils may have perceptions and attitudes that a teacher could never predict.

- That there is a significant affective element to awareness of writing, which teachers should also account for in their methods.

However, to conclude, metalanguage must be taken only as part of metalinguistic awareness, which cannot operate alone. It is one factor in a composite skill which necessarily requires others in order to function. Like the golfer who can putt beautifully but cannot drive or chip by any description, a pupil with good metalanguage alone does not have all the skills with which to play the 'language game' with skill. However, it seems to be one necessary factor in language use and development, and seems to be significant in terms of both range and context of application to pupils' written language development. Only further studies will be able to ascertain this. 


\section{Correspondence}

For further details of either the range of questions, the pupil responses or the questions that arose in the interviews, please contact Melanie Robinson, University of Warwick, UK (melanie.robinson@warwick.ac.uk).

\section{Notes}

1. The term metalanguage is used in this study to denote what Berry (this volume) refers to as 'applied metalanguage', i.e. it is natural metalanguage, that which occurs within languages to describe and refer to themselves. Metalanguage is therefore reflexive, is not a distinct language, and tends to be imprecise in its nature.

2. Metalinguistic awareness is here taken to mean knowledge and awareness of language, not knowledge and awareness of metalanguage. The term 'metalingual awareness', from Berry (see this volume) is the term applied to awareness of metalanguage.

3. Metalanguage terminology is used to indicate only the lexis of metalanguage, i.e. words such as sentence, report, write, say, etc.; there are other elements of metalanguage that have not been accounted for here, such as reflexive grammatical constructions, and the lexis of metadiscourse for example.

4. The GCSE (General Certificate in Secondary Education) is regarded as the most basic educational qualification in the UK; the implication of this is that further development after the age of 16 is still possible).

5. To contextualise briefly, level 8 is the highest level a pupil can achieve at this age (with only Level EP [Exceptional Performance] indicating even higher ability). Performance at the level $4 / 5$ borderline is average for Year 8 , the year group that these pupils are from (age 12-13 years). Level 2 is far below average ability for chronological age, and level 6 is significantly higher.

\section{References}

Baker, C. and Freebody, P. (1989) Talk around text: Constructions of textual and teacher authority in classroom discourse. In S. De Castell, A. Luke and C. Luke (eds) Language, Authority and Criticism: Readings on the School Textbook. London: Falmer.

Bereiter, C. and Scardamalia, M. (1987) The Psychology of Written Composition. Hillsdale, NJ: Erlbaum.

Berry, R. (2005) Making the most of metalanguage. Language Awareness 14 (1), 3-20.

Cioffi, G. (1984) Observing composing behaviours of primary-age children: The interaction of oral and written language. In R. Beach, and L.S. Bridwell (eds) New Directions in Composition Research. New York: Guildford.

Dahl, K.L. and Freppon, P. (1985) A comparison of inner-city children's interpretations of reading and writing instruction in the early grades in skills-based and whole-language classrooms. Reading Research Quarterly 31, 50-75.

Davis, H.G. (2001) Words: An Integrational Approach. Richmond: Curzon.

Davis, H.G. (2003) Introduction. In H.G. Davis and T.J.Taylor (eds) (2003) Rethinking Linguistics. London: Routledge Curzon.

DfEE (1999) The National Curriculum for England. London: DfEE QCA.

DfES (2001) The National Literacy Strategy: Framework for Teaching English, Years 7, 8 and 9. London: DfES.

Dyson, A.H. (1989) Multiple Worlds of Child Writers: Friends Learning to Write. New York: Teachers College.

Dyson, A.H. (1991) Viewpoints: The word and the world - reconceptualizing written language development, or do rainbows mean a lot to little girls? Research in the Teaching of English 25, 97-123.

Dyson, A.H. (1992) Whistle for Willie, lost puppies and cartoon dogs: The sociocultural dimensions of young children's composing. Journal of Reading Behavior 24 (4), 433-61.

Graves, D. (1983) Writing: Teachers and Children at Work. Portsmouth NH: Heinemann.

Halliday, M.A.K. and Hasan, R. (1976) Cohesion in English. London: Longman. 
Hannan, G. (2001) Successful People Successful Learners. Much Wenlock: Hannan Training and Consultancy.

Harris, R. (1996) The Language Connection. Bristol: Thoemmes.

Harris, R. (1998) Introduction to Integrational Linguistics. Oxford: Elsevier.

MacGillivray, L. (1994) Tacit shared understandings of a first-grade writing community. Journal of Reading Behavior 26 (3), 245-66.

Myhill, D. (2001) Better Writers. London: Westley Courseware.

Ong, W. (1982) Orality and Literacy: The Technologising of the Word. London: Methuen.

Rampton, B., Roberts, C., Leung, C. and Harris, R. (2002) Methodology in the analysis of classroom discourse. Applied Linguistics 23 (3), 373-92.

Taylor, T.J. (2000) Language constructing language: The implications of reflexivity for linguistic theory. Language Sciences 22, 483-99.

Taylor, T.J. (2003) Language constructing language: The implications of reflexivity for linguistic theory. In H.G. Davis and T.J. Taylor (eds) Rethinking Linguistics. London: Routledge Curzon. 